

\section{Panta Rei \\ Revista Digital de Ciencia \\ y Didáctica de la Historia}

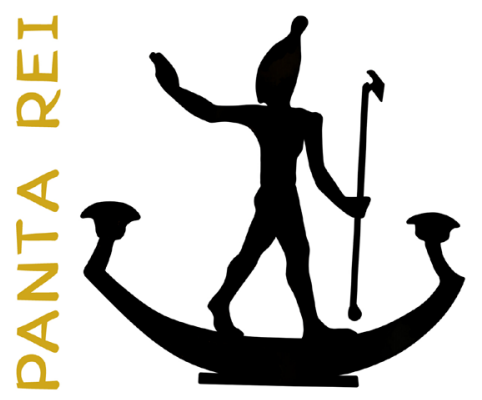

2017

Revista anual

Fecha de inicio: 1995

Revista Panta Rei. pantarei@um.es

Edita:

Centro de Estudios del Próximo Oriente y la

Antigüedad Tardía - CEPOAT

Edificio Universitario Saavedra Fajardo.

Universidad de Murcia

C/ Actor Isidoro Máiquez, 9

30007 - MURCIA - ESPAÑA

Teléfono: (+34) 868883890

cepoat@um.es

Web: www.um.es/cepoat/pantarei

Edición 2017

ISSNe: 2386-8864

ISSN: 1136-2464

Depósito legal: MU-966-1995
cepoAt

UNIVERSIDAD DE MURCIA centro de estudios del próximo oriente y la antigüedad tardia

En Portada: Kaaba durante el Ramadán. Fotografía de Abdullah Shakoor. Creative Commons CCO.

Responsables de los textos: Sus autores.

Responsable de la presente edición: Consejo Editorial Panta Rei. 


\section{CONSEJO DE REDACCIÓN}

\section{Coordinador editorial}

Egea Vivancos, Alejandro

[Didáctica de las Ciencias Sociales, UMU]

\section{Editores}

Botí Hernández, Juan Jesús

[CEPOAT, UMU]

Meseguer Gil, Antonio José

[UNED]

Sáez Giménez, David Omar

[CEPOAT, UMU]

Sánchez Mondéjar, Celso Miguel

[Patrimonio Inteligente]

\section{Secretaria}

Arias Ferrer, Laura

[Didáctica de las Ciencias Sociales, UMU]

\section{Responsable informático}

Martínez García, José Javier

[CEPOAT, UMU]

\section{Traducción y corrección lingüística}

Martínez Martínez, Cristina

[Sociedad Española de Lenguas Modernas]

Albaladejo Albaladejo, Sara

[ISEN, UMU]

\section{CONSEJO ASESOR}

Albero Muñoz, M. ${ }^{a}$ del Mar

[H. ${ }^{a}$ del Arte, UMU]

Chapman, Arthur

[History Education, UCL, Reino Unido]

Cobacho López, Ángel

[Derecho, UMU]

Egea Bruno, Pedro M. ${ }^{a}$

[Historia Contemporánea, UMU]

García Atienzar, Gabriel

[Prehistoria, UA]

González Monfort, Neus

[Didáctica de las Ciencias Sociales, UAB]

Haber Uriarte, María

[Prehistoria, UMU]

Hutson, Scott R.

[Anthropology, UK, EEUU]

Irigoyen López, Antonio

[Historia Moderna, UMU]

Mahony, Simon

[Digital Humanities, UCL, Reino Unido]

Marsilla de Pascual, Francisco Reyes

[Técnicas historiográficas, UMU]

Miralles Maldonado, José Carlos

[Filología Clásica, UMU]

Molina Gómez, José Antonio

[Historia Antigua, UMU]

Noguera Celdrán, José Miguel

[Arqueología, UMU]

Pérez Molina, Miguel Emilio

[Filología Clásica, UMU]

Prados Martínez, Fernando

[Arqueología, UA]

Sánchez Ibáñez, Raquel

[Didáctica de las Ciencias Sociales, UMU]

Sancho Gómez, Miguel Pablo

[Educación, UCAM]

Vilar García, María José

[Historia Contemporánea, UMU]

Zamora López, José Ángel

[Próximo Oriente Antiguo, CCHS-CSIC] 

Artículos

Entre el mito y la historia: el Éxodo de los israelitas desde Egipto a Canaán.

David Villar Vegas.

El Cerro de la Ermita de La Encarnación (Caravaca de la Cruz, Murcia): santuario y territorio en el mundo ibérico del Sureste peninsular.

Leticia López-Mondéjar.

Estelas discoideas y mundo funerario en la Asturias antigua.

Narciso Santos Yanguas......

Filosofía y paganismo en las postrimerías del Imperio Romano de Occidente. El caso del cónsul Mesio Febo Severo.

Rafael González Fernández y Miguel Pablo Sancho Gómez.

Dinámicas identitarias en el Mundo Actual: la religión como identidad frente al otro.

Rafael Ruiz Andrés y Francisco Javier Fernández Vallina.

El patrimonio fenicio-púnico. Claves para su socialización, puesta en valor y uso didáctico.

Helena Jiménez Vialás.

¿Cómo se enseña la llustración en $22^{\circ}$ de Bachillerato? Un análisis de los libros de texto, sus contenidos y la cuestión de género.

Helena Rausell Guillot..... 109

The Role of Local History in Elementary and Secondary Schools in Slovenia: An Evaluation of the Centre for School and Outdoor Education.

Danijela Trškan

Reseñas

Richardson, S. y Garfinkle, S. (eds.) (2016). Scholarship and Inquiry in the Ancient Near East (=Journal of Ancient Near Eastern History special issue, vol. 2/2, 2015) Berlin: de Gruyter. 179 págs.

Juan Álvarez García.

Guldi, J. y Armitage, D. (2016). Manifiesto por la Historia (traducción de Galmarini, M. A. The History Manifesto, 2014). Madrid: Editorial Alianza. 292 págs.

Juan Jesús Botí Hernández y David Omar Sáez Giménez.....

Normas de publicación/Publishing rules 



\title{
El Cerro de la Ermita de La Encarnación (Caravaca de la Cruz, Murcia): santuario y territorio en el mundo ibérico del Sureste peninsular ${ }^{1}$
}

\author{
The Cerro de la Ermita of La Encarnación (Caravaca de la Cruz, Murcia): cult place \\ and territory in the Iron Age Iberian Southeast
}

\author{
Leticia López-Mondéjar² \\ Instituto de Ciencias del Patrimonio - Incipit (CSIC)
}

Recibido: 31/01/2017

Aceptado: 06/04/2017

Para citar este artículo: López-Mondéjar, L. (2017). El Cerro de la Ermita de La Encarnación (Caravaca de la Cruz, Murcia): santuario y territorio en el mundo ibérico del Sureste peninsular. Panta Rei. Revista Digital de Ciencia y Didáctica de la Historia, 23-40.

ISSNe: 2386-8864

DOI: $10.6018 /$ pantarei/2017/2

\section{Resumen}

Los lugares de culto, como elementos del paisaje, desarrollaron un papel fundamental a nivel territorial entre las comunidades protohistóricas mediterráneas, incluido el propio mundo ibérico. Dicho papel ha sido sin embargo escasamente estudiado en el ámbito del Sureste y, concretamente, en el caso del importante santuario localizado en La Encarnación (Caravaca, Murcia). El objetivo del presente trabajo es insertar dicho lugar de culto en su contexto espacial, analizando su papel territorial desde una triple perspectiva: en conexión con el oppidum, en relación con el territorio vinculado a éste y, finalmente, su papel más allá del territorio de dicho oppidum.

\section{Palabras clave}

Yacimientos, Arqueología, Historia local, Entorno urbano, Organizaciones religiosas.

\section{Abstract}

As part of the landscape cult places developed an essential territorial role in the Mediterranean Protohistoric societies, including the Iberian communities. This role has not received the wide attention that it deserves in the Iberian Southeast, and particularly in the case study of the important sanctuary located in La Encarnación (Caravaca, Murcia). The aim of this paper is to insert this cult place within its spatial context and to analyze its territorial role from three perspectives: in connection with the oppidum, in relation to the territory controlled by this centre and, finally, beyond the territorial area of the oppidum.

1 Esta investigación está financiada por el Programa Horizon 2020 de la Unión Europea a través de las acciones Marie Sklodowska-Curie Individual Fellowships (GA 654906).

2 Para contactar con la autora: Leticia López-Mondéjar. Instituto de Ciencias del Patrimonio, Incipit-CSIC. leticia.lopez-mondejar@incipit.csic.es. 


\section{Keywords}

Historic sites, Archaeology, Local History, Urban Environment, Religious Organizations.

\section{Introducción}

Los lugares de culto, como parte integrante del paisaje, ofrecen información clave para el estudio de las sociedades ibéricas. Así lo han demostrado los estudios desarrollados en diversas áreas mediterráneas donde estos espacios se presentan como elementos esenciales para comprender la organización territorial de dichas comunidades (Alcock y Osborne, 1994; Cultraro, 2005; Witcher, 1999). Esta perspectiva, sin embargo, está prácticamente ausente en el estudio de los santuarios ibéricos del Sureste peninsular, donde se localizan algunos de los más destacados y conocidos del mundo ibérico: La Encarnación (Caravaca de la Cruz), El Cigarralejo (Mula), Coimbra del Barranco Ancho (Jumilla) o La Luz (Verdolay, Murcia). Los trabajos que han abordado el análisis de dichos yacimientos han ofrecido numerosos datos relativos a su cultura material y su desarrollo, sin embargo, se echa en falta un estudio de los mismos dentro de su marco territorial y una mayor profundización en su papel sociopolítico.

Afortunadamente, recientes estudios desarrollados en esta zona peninsular han permitido conocer con más detalles la evolución del poblamiento y la articulación del territorio desde época ibérica y hasta la presencia romana. Entre las zonas que han sido analizadas desde este punto de vista queda el sector del Noroeste murciano y el valle del Quípar (Brotóns y López-Mondéjar, 2010; López-Mondéjar, 2009), donde precisamente se localiza uno de los ejemplos más interesantes dentro de los lugares de culto de todo el Sureste peninsular: el santuario del Cerro de la Ermita de La Encarnación (Figura 1). Si el desarrollo que este yacimiento experimenta con la presencia romana es bien conocido a través de los trabajos de F. Brotóns y S. Ramallo, menos datos se tienen en cambio sobre la fase previa a la misma, correspondiente a los siglos IV-III a.C. ${ }^{3}$ Ésta, sin embargo, resulta clave para comprender tanto la transformación edilicia del santuario en las centurias siguientes como su continuidad frente a otros lugares de culto regionales.

Partiendo de dicho panorama, nuestro objetivo es insertar el santuario de La Encarnación en el paisaje ibérico de los siglos IV-III a.C., aproximándonos a su relación con otros elementos del mismo (asentamientos, vías de comunicación, etc.) que nos permitan definir el posible papel que dicho lugar de culto pudo desempeñar en esas centurias en este territorio. Si bien algunas cuestiones han sido tratadas de forma individual en estudios previos, el objetivo de este trabajo es ofrecer una síntesis y una revisión global de todas ellas, que permita mostrar una imagen más completa de dicho santuario en el marco del paisaje y el poblamiento de esta zona del Sureste. Para ello, atendiendo a los estudios desarrollados en otros ámbitos del Mediterráneo y de la propia Península Ibérica, analizaremos dicho santuario a varios niveles. Así, abordaremos su conexión con el núcleo principal, su relación con otros yacimientos documentados en el territorio del oppidum y, finalmente, su análisis en un marco más amplio, que irá más allá de los límites definidos por este último.

Para atender a estos aspectos hemos partido de la información ofrecida por la Carta Arqueológica regional para este sector murciano. Ésta ha sido posteriormente revisada y completada gracias a los datos aportados por los últimos estudios indicados, por los trabajos de prospección realizados desde la Universidad de Murcia en la zona del Estrecho de las Cuevas ${ }^{4}$, y mediante la visita a aquellos yacimientos más problemáticos de este sector regional. Partiendo de dichos datos

3 Entre dichos trabajos cabe señalar los de Brotóns y Ramallo, 1994, 1999 y 2010; Ramallo, 1991 y 1993; Ramallo y Arana, 1993; y Ramallo y Brotóns, 1997 y 1999.

4 Dichos trabajos fueron realizados dentro del proyecto de investigación "Prospección arqueológica de Los Villaricos en el sitio histórico del Estrecho de las Cuevas de La Encarnación (Caravaca de la Cruz, Murcia)" y dirigidos por S. F. Ramallo Asensio (Universidad de Murcia). 
es posible esbozar brevemente, como paso previo al análisis del santuario desde los tres niveles indicados, aquellos rasgos que caracterizan la localización de La Encarnación en el paisaje del Noroeste murciano y que definen el valle del Quípar durante los siglos IV-III a.C. No es nuestro objetivo analizar la amplia documentación asociada a este santuario y ya publicada en numerosos trabajos, sino sintetizar aquellos rasgos del yacimiento que consideramos de especial interés para enmarcar el triple análisis planteado y, en definitiva, comprender su papel en el paisaje ibérico de esta zona a partir del siglo IV a.C.

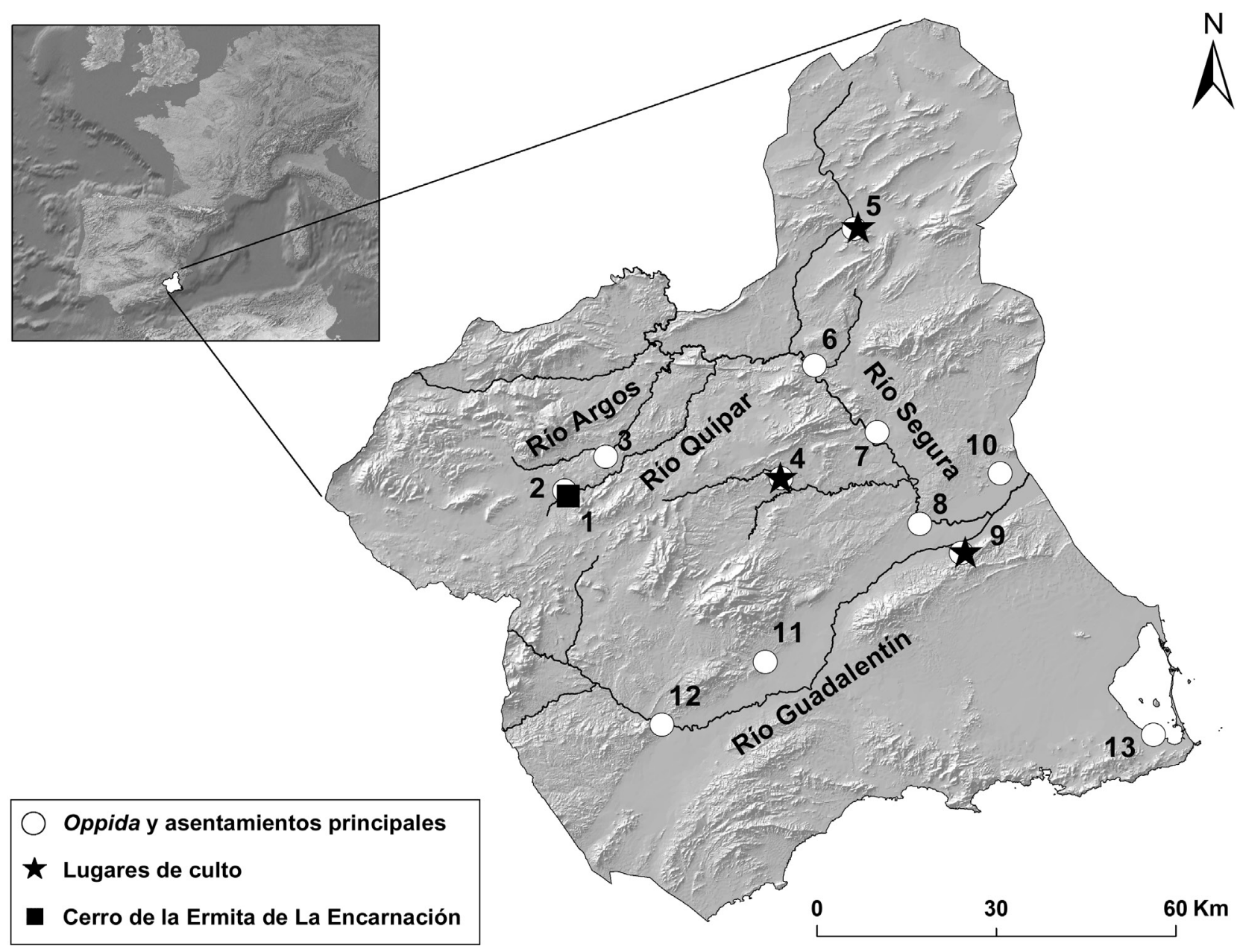

Figura 1. Localización del Cerro de la Ermita de La Encarnación en el Sureste peninsular y principales núcleos y santuarios ibéricos citados en el texto (1.La Encarnación, 2.Los Villaricos, 3.Cabezo Roenas, 4.Santuario y oppidum del Cigarralejo, 5.Santuario y oppidum de Coimbra del Barranco Ancho, 6.Bolvax, 7.Cabezo del Tío Pío, 8.Cabezo de la Rueda, 9.La Luz y Santa Catalina del Monte, 10.Cobatillas la Vieja, 11.Las Cabezuelas, 12.Cerro del Castillo de Lorca, 13.Loma del Escorial). Fuente: elaboración propia.

\section{El mundo ibérico en el valle del Quípar entre los siglos IV-III a.C.}

El Cerro de la Ermita de La Encarnación, cerca de la actual población de Caravaca de la Cruz, constituye uno de los yacimientos mejor conocidos de la Región de Murcia. Localizado en el Estrecho de las Cuevas, en el valle del Quípar, se sitúa en un punto de paso natural y obligado en el acceso al valle del Segura desde tierras andaluzas, junto al que discurren además numerosas vías pecuarias (Figura 2).

Los primeros datos sobre la ocupación de este sector del valle se remontan a época prehistórica y su importancia en la historia regional es clara si atendemos a las numerosas menciones de eruditos 
locales y estudiosos que ya desde el siglo XVII se refieren a los restos arqueológicos documentados en la zona (Cuadrado, 1945; Yelo, 1984). El sector en el que se ubica el santuario presenta además un marcado carácter forestal que, unido a su amplia visibilidad sobre el valle y a la presencia de agua en las inmediaciones, definió el carácter especial de esta zona ya desde época antigua, influyendo sin duda en la elección del emplazamiento de dicho lugar de culto. En este sentido, la perduración hasta época romana del culto en esta zona y la posterior construcción, ya en el siglo XVII, de una ermita sobre los restos de aquel santuario, reflejan la continuada percepción de esta área como un sector con un carácter especial dentro del paisaje del valle.

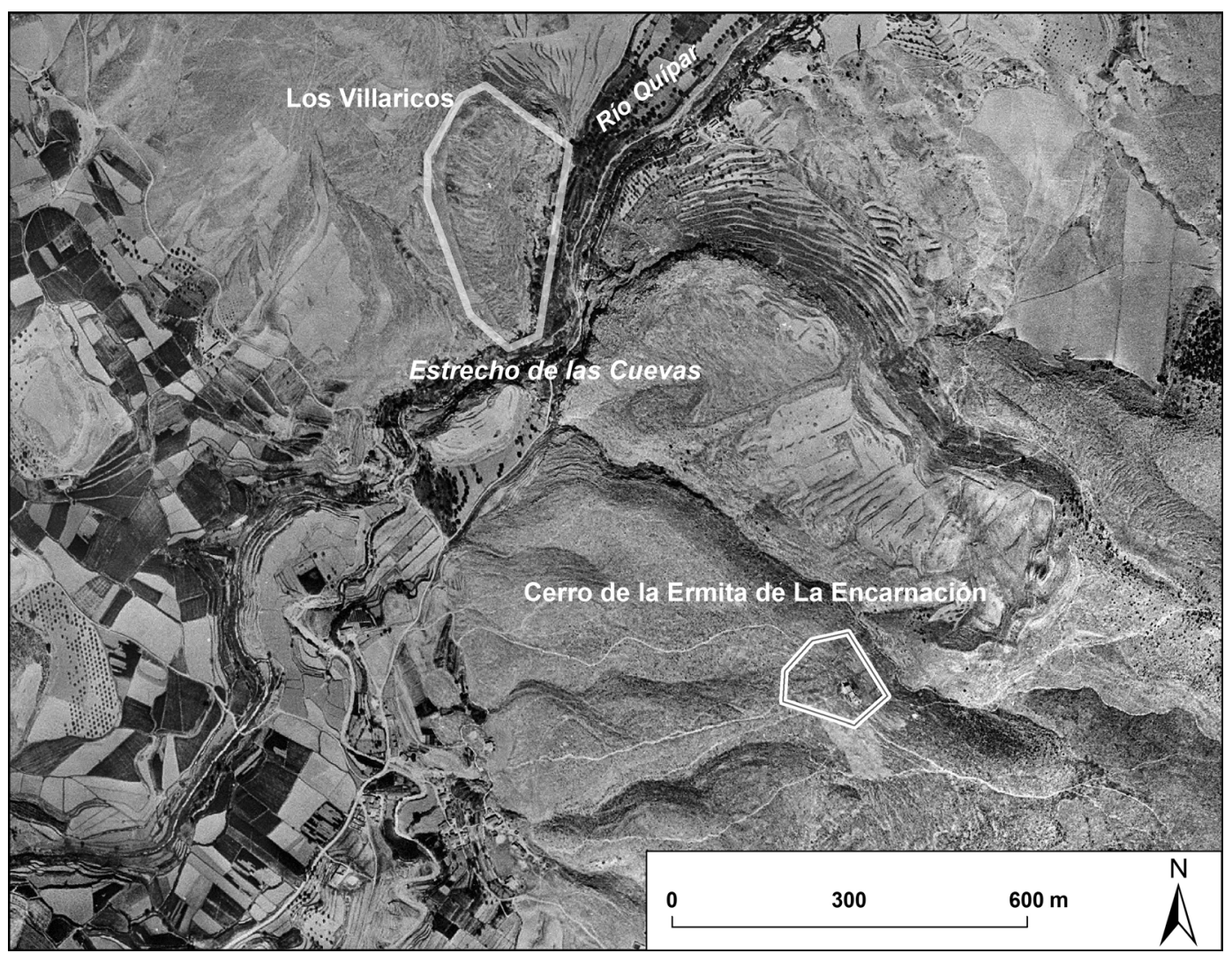

Figura 2. Localización del santuario de La Encarnación y del oppidum ibérico de Los Villaricos en el Estrecho de las Cuevas. Fuente: elaboración propia.

Volviendo al periodo que nos ocupa, el Estrecho de las Cuevas se presenta además durante los siglos IV-III a.C. como un sector de especial interés ya que es precisamente allí donde se localiza el núcleo ibérico más importante del valle: el oppidum de Los Villaricos. Se trata de un amplio asentamiento, de unas 7 ha de extensión, y emplazado en la margen izquierda del Quípar, en un cerro frente al santuario de La Encarnación. El yacimiento aparece amurallado en su perímetro, especialmente en el sector occidental, el más fácilmente accesible y donde se localiza la entrada al oppidum. Los materiales recuperados en superficie durante las prospecciones realizadas apuntan a una amplia cronología para el yacimiento ibérico, que continuó ocupado durante el periodo imperial. Desafortunadamente, el escaso conocimiento que aun hoy tenemos de la necrópolis de Los Villaricos, nos impide una mejor aproximación, especialmente desde el punto de vista social, a dicho asentamiento. Aun así, los interesantes paralelos que ofrecen otros oppida regionales, cuyas necrópolis son ampliamente conocidas (El Cigarralejo, Coimbra del Barranco Ancho, Cabecico del Tesoro), sirven sin duda como referencias esenciales para comprender el papel desempeñado por este centro ibérico del Noroeste murciano a nivel sociopolítico y territorial.

De este modo, el registro material, la amplia extensión, la decisión locacional y las murallas 
de Los Villaricos diferencian claramente a este centro del resto de los núcleos documentados en este sector regional, situándolo a la cabeza del poblamiento en el mismo (López-Mondéjar, 2010a). El panorama aparece así marcado en el siglo IV a.C. por un modelo de poblamiento cohesionado y organizado por dicho núcleo principal, junto al que se documentan también durante esa centuria y la siguiente toda una serie de asentamientos de carácter secundario en cuanto a su extensión, registro material y emplazamiento. Surgidos en su mayoría en el IV a.C., aparecen distribuidos a lo largo del valle y próximos tanto a aquellos suelos más aptos para el desarrollo de actividades agropecuarias como a las vías naturales de comunicación que constituyen los cursos fluviales (Brotóns, 1995; López-Mondéjar, 2010a).

Entre dichos yacimientos, algunos ocuparon posiciones estratégicas en conexión con los ejes de comunicación comarcales, como el Cerro de la Cueva IV, si bien nunca adquirieron una entidad similar a la del oppidum (Figura 3). Precisamente vinculados a dichos centros aparecen sectores de necrópolis, cuyos ajuares y la diversidad tipológica de sus enterramientos, como se observa en El Villar de Archivel, reflejan la complejidad social alcanzada por estas comunidades (Brotóns, 2008). Junto a algunos de esos núcleos rurales se desarrollaron también pequeños lugares de culto al aire libre similares a los documentados en el norte granadino, y cuya cultura material, al igual que su emplazamiento y su cronología muestran un carácter distinto al del santuario de La Encarnación (Adroher y López 2004; López-Mondéjar, 2010b).

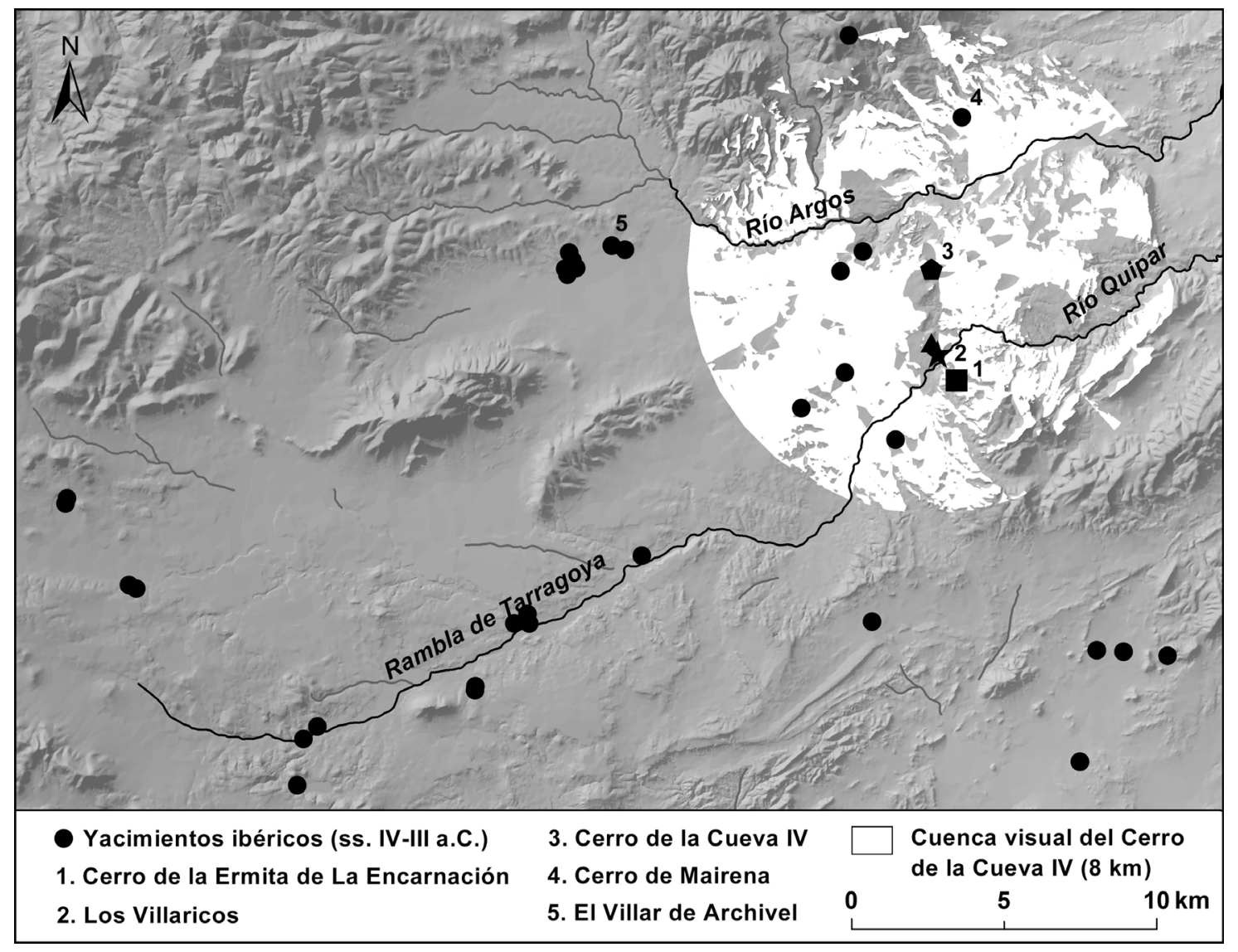

Figura 3. Distribución de los yacimientos ibéricos de los siglos IV-III a.C. en el valle y control visual del Cerro de la Cueva IV. Fuente: elaboración propia.

El valle aparece de este modo definido, durante los siglos IV-III a.C., por un paisaje jerarquizado en torno al oppidum de Los Villaricos (López-Mondéjar 2010a). Es precisamente en este contexto en el que cabe encuadrar el primer nivel de análisis del santuario de La Encarnación. 


\section{El Cerro de la Ermita de La Encarnación y el oppidum de Los Villaricos}

Como se ha indicado para otros ámbitos del Mediterráneo prerromano, también en el área ibérica se ha vinculado el desarrollo de los lugares de culto con el proceso de reafirmación territorial de los oppida. Desde esta perspectiva, tales espacios se presentan como elementos clave en el paisaje y su vinculación a esos centros principales como un aspecto decisivo para sancionar el papel desempeñado por éstos en el territorio de su entorno.

Teniendo en cuenta este planteamiento, una de las primeras cuestiones que surge al analizar el santuario de La Encarnación desde dicha perspectiva es si el desarrollo de este lugar de culto estuvo también en conexión con un proceso similar. En este sentido, es fundamental atender a aquellos aspectos que permiten poner en conexión este yacimiento con el vecino oppidum de Los Villaricos. Entre ellos atenderemos aquí particularmente a tres: la cronología que ofrecen ambos yacimientos, su emplazamiento y, finalmente, la presencia en el santuario de una serie de elementos que pueden ser vinculados directamente con la élite residente en dicho oppidum.

Por lo que respecta a la cronología, el origen de ambos yacimientos ha sido datado en el siglo IV a.C., coincidiendo así con el momento de desarrollo de los grandes oppida ibéricos del Sureste (Ros, Brotóns y Ramallo, 2016). Estos centros aparecen en el paisaje ibérico de dicha centuria como núcleos articuladores de los distintos valles regionales, dominando las principales vías de comunicación y controlando el poblamiento secundario localizado en las zonas bajas. El desarrollo de estos oppida fue coetáneo además con el de otros santuarios ibéricos en toda la zona murciana, siguiendo un esquema similar al que se ha planteado para las áreas alicantina y andaluza (Grau, 2010). En esta última los santuarios surgen también al amparo de grandes núcleos fortificados y su aparición y desarrollo se ha interpretado como parte de un proceso más amplio, marcado por la consolidación del poder de dichos oppida en el territorio (Ruiz y Molinos, 2002, p. 293). En el caso del Noroeste murciano, la cronología de ambos yacimientos, La Encarnación y Los Villaricos, así como los cambios que se observan en el poblamiento del valle del Quípar a partir de esa cuarta centuria, apuntan también a un proceso similar, y presentan al santuario como un elemento fundamental en el paisaje de este sector y claramente ligado al vecino oppidum.

Otro de los aspectos señalados que refleja más claramente la relación entre los dos yacimientos es su emplazamiento en el valle. En este caso, dicha conexión es expresada espacialmente a través de una directa vinculación topográfica. Oppidum y santuario aparecen localizados, como indicábamos, en el sector conocido como el Estrecho de Las Cuevas, un área clave de paso en la que el cauce del Quípar se estrecha para discurrir entre los cerros en los que, a ambos lados del río, se emplazan dichos yacimientos (Figura 2). Separados únicamente por el curso fluvial, tanto el hábitat como el lugar de culto ejercen un control conjunto sobre el eje natural que representa dicho río y sobre todo el valle medio y alto del mismo, ruta natural hacia la Alta Andalucía.

Finalmente, en cuanto al último de los aspectos señalados, cabe indicar la presencia de otra serie de elementos que dejan ver también la conexión entre santuario y oppidum, permitiendo observar la participación de la élite indígena en el lugar de culto, una élite que, a juzgar por los datos aportados por los yacimientos comarcales, habría residido principalmente en el núcleo emplazado en Los Villaricos. Los materiales recuperados en el santuario, y concretamente los datados durante el periodo ibérico, constituyen sin duda un elemento clave para analizar dicha conexión. Entre ellos uno de los mejores ejemplos son los exvotos en piedra. En ellos se representan personajes ricamente ataviados y guerreros, cuyos atributos y actitudes permiten vincularlos a grupos destacados dentro de la sociedad (Aranegui, 1994; Ramallo y Brotóns, 2014; Ramallo, Noguera y Brotóns, 1998; Ruano y San Nicolás, 1993) (Figura 4). De este modo, las imágenes que vemos en La Encarnación, y que aparecen también en otros lugares de culto del Sureste, estuvieron asociadas a las élites dado que los símbolos que representan se vincularon sin duda al prestigio, el estatus y la fuerza, tal y como ocurrió en otras áreas del Mediterráneo (Bradley, 1997; Cardete, 2003; Colonna, 1985). Éstos, se convirtieron así en espacios de representación para las élites locales, en los que a través de dicha iconografía y los símbolos a ella asociados se expresaron los valores de dicho grupo social 
diferenciándolo de otros miembros de la comunidad (López-Mondéjar, 2014).
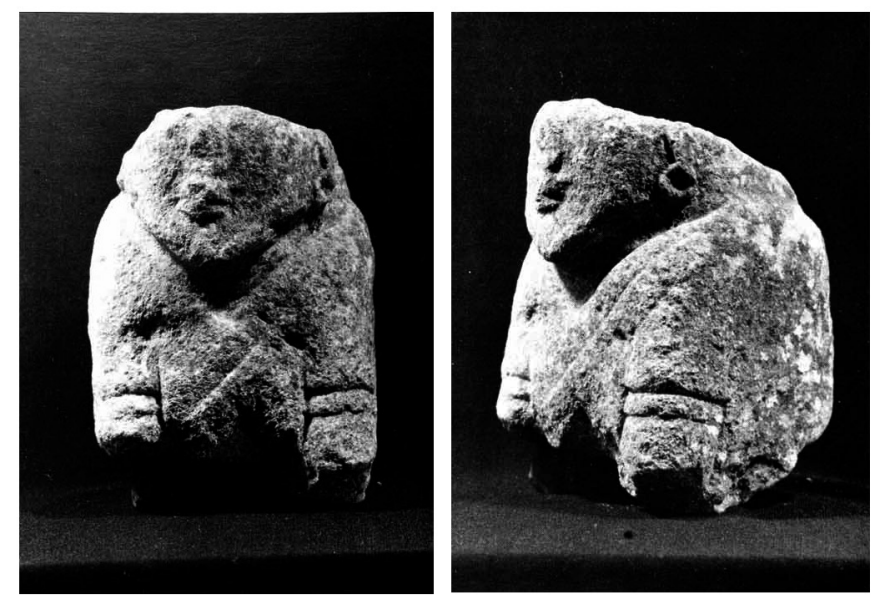

Figura 4. Exvoto de guerrero en piedra recuperado en el santuario de La Encarnación (a partir de Ruano y San Nicolás, 1993, Fig. 9).

En el caso de La Encarnación, la presencia de falcatas votivas y de elementos realizados en metales preciosos, especialmente plaquitas (Ramallo, 1993), puede interpretarse también en esta misma línea y, en última instancia, dichos elementos constituyen expresiones de la élite. Entre las plaquitas halladas en el yacimiento resulta interesante una de plata repujada en la que aparece un personaje antropomorfo de perfil con la oreja y el ojo acentuados. Tanto su atavío como el modelo de representación de la figura, que carece de la gestualidad frontal propia de las divinidades ibéricas, han llevado a ponerla en relación con un posible dignatario miembro de la élite que probablemente desempeñó funciones 'sacerdotales' (Brotóns y Ramallo, 2010, pp. 141-142). La vinculación entre santuario y oppidum va así más allá de su mera conexión topográfica, constituyendo el primero un espacio de representación ideal para la élite residente en Los Villaricos que, a través de exvotos y representaciones, y también mediante su participación en determinadas ceremonias, lograría consolidar su papel dentro de la comunidad.

Finalmente, un último aspecto que apunta a la relación directa entre ambos yacimientos, oppidum y santuario, lo constituye el desarrollo que experimenta este último durante los primeros momentos de la presencia romana en el Sureste. Tanto la transformación edilicia de La Encarnación como su pervivencia durante el periodo romano sólo pueden entenderse en conexión con la importancia adquirida por el vecino oppidum de Los Villaricos y con su continuidad durante el periodo imperial, tal y como reflejan los materiales recuperados en las prospecciones realizadas en el cerro. El interés romano por mantener el status quo en la zona y garantizar la estabilidad durante los primeros momentos de su presencia en el Sureste, parece haberse traducido en el apoyo al núcleo principal y articulador de todo este territorio, alejado de Carthago Nova y de la directa actuación romana en estos momentos. Precisamente la monumentalización que experimenta el santuario, con la construcción de dos templos de estilo itálico, cuyos materiales fueron directamente importados desde el Lacio (Ramallo, 1991), ha querido ser vista como respuesta de Roma a la 'amistad' de las élites locales residentes en Los Villaricos (Ramallo, 1993, p. 133). Es en este marco donde cabe comprender también la continuidad del oppidum durante el periodo romano y frente a la desaparición de otros importantes núcleos ibéricos regionales. Los Villaricos será el único centro ibérico del valle que se mantendrá ocupado en época imperial, siendo mencionado en la epigrafía como Res Publica ya en el siglo II d.C. (Yelo, 1984).

En general, todos los aspectos indicados, vinculan directa e indirectamente el santuario de La Encarnación con el vecino oppidum de Los Villaricos y con la élite residente en este centro. Dicha conexión entre ambos yacimientos y la importancia alcanzada por el lugar de culto como 
espacio de representación social fueron sin duda claves en el desarrollo experimentado por éste, sin embargo, ¿fueron los únicos factores que favorecieron el desarrollo de este santuario? Atendiendo a la monumentalización experimentada por el mismo con la llegada de Roma se plantea una cuestión fundamental: ¿es posible que dicho yacimiento tuviese un rol más amplio, es decir, más allá de esa relación directa con el oppidum y la élite local? En este sentido, ¿pudo haber jugado un papel destacado en el territorio o simplemente constituyó un espacio vinculado exclusivamente a ese oppidum? Se trata de un aspecto fundamental para comprender el desarrollo de La Encarnación, especialmente si se tiene presente que se trata del único lugar de culto ibérico del Sureste que ofrecerá una clara continuidad durante los períodos republicano e imperial.

Precisamente para abordar dichas cuestiones cabe atender al segundo de los niveles de análisis indicados, ampliando nuestra perspectiva más allá del oppidum e insertando el santuario en el marco del valle del Quípar.

\section{El Cerro de la Ermita en el valle del Quípar y el territorio del oppidum}

A la hora de abordar el análisis del santuario de La Encarnación en el valle del Quípar, varios aspectos permiten aproximarnos al carácter que definió su localización dentro del paisaje de este sector regional así como al significado que pudo tener dentro del mismo. En este sentido, los trabajos desarrollados en la zona alicantina y también en la andaluza constituyen un punto de referencia esencial. En ellos se ha analizado el papel de esos santuarios como elementos clave en la construcción del espacio político y, por tanto, en los procesos de territorialización de los grupos ibéricos desde el ámbito local al regional (Grau, 2011).

Volviendo al caso de La Encarnación resulta especialmente interesante atender a tres aspectos fundamentales que, sin duda, nos aportan información en esta línea: la visibilidad de dicho lugar de culto en el territorio, su conexión con las vías de comunicación y, finalmente, su relación con el poblamiento del valle.

Por lo que respecta al primero de dichos aspectos, una de las cuestiones que llaman la atención en conexión con la localización del santuario es su amplia cuenca visual, orientada precisamente hacia aquellas zonas en las que se concentra el poblamiento durante este periodo (Figuras 5 y 6). Al mismo tiempo, se localiza en un punto visible desde prácticamente cualquier sector del valle, y ofrece una clara conexión visual con aquellos núcleos y sectores más destacados dentro del territorio, como los localizados en Archivel y en el entorno del Cerro del Carro (Las Carrasquicas, Cabezo de la Fuente de los Morales). Si bien toda esta zona del Noroeste murciano pudo estar condicionada por la meteorología en determinados momentos del año, como pueden ser los meses invernales, en general todo el valle ofrece buenas condiciones visuales. Así, incluso desde el señalado Cerro del Carro, distante más de $19 \mathrm{~km}$ del área del Estrecho de las Cuevas, es posible advertir el emplazamiento del santuario y del oppidum de Los Villaricos.

Un segundo aspecto de interés es aquel relativo a la conexión entre el santuario y las vías de comunicación que atraviesan este sector regional. Ya hemos comentado la posición estratégica de La Encarnación, la cual, unida a su amplia visibilidad sobre el valle, le otorgó un claro control sobre la ruta natural que, desde tierras granadinas, alcanzaba el valle del Segura y el Levante peninsular. Dicha localización tuvo así una doble implicación. Por un lado el santuario constituyó un punto de control 'complementario' al oppidum en el valle; por otro, dicha posición pudo haber tenido además claras implicaciones económicas para ambos yacimientos (Angás, 2005; Zifferero, 2002).

Resultado también de dicha localización, como ya indicaba S. Ramallo, es la presencia de ciertos rasgos visibles en el plano artístico y en los elementos de culto del santuario, en los que se observan influencias foráneas. En este sentido se ha interpretado la presencia de una columna sagrada, que vemos representada en diferentes motivos en otros santuarios del Sureste localizados asimismo en ejes destacados de comunicación como La Luz y el Cerro de los Santos (Brotóns, 2007; García, 2015; Ramallo, 2000). A ello cabe sumar la iconografía simbólica que caracteriza muchos de los materiales recuperados, identificados con el ajuar de la divinidad (Ramallo y Brotóns, 
2010). Entre éstos destacan, por ejemplo, dibujos esquemáticos de espiguillas, inusuales en el ámbito ibérico y para los que Ramallo y Brotóns (2010) han apuntado un posible origen púnico. También en esta línea cabe recordar el origen foráneo que este último autor ha propuesto para un conjunto de terracotas del santuario (Serie II), cuya excepcionalidad y la ausencia de paralelos peninsulares podrían remitir al área sarda (Brotóns, 2007). Por último, tampoco podemos olvidar la relación que se ha establecido, a nivel iconográfico, entre este tipo de terracotas y el mundo púnico (Aranegui, 2011). Todos estos elementos podrían así interpretarse como reflejo de los intercambios económicos y culturales asociados a dicha vía de comunicación, denotando la inserción de esta área, en principio aparentemente interior y aislada, en circuitos más amplios.

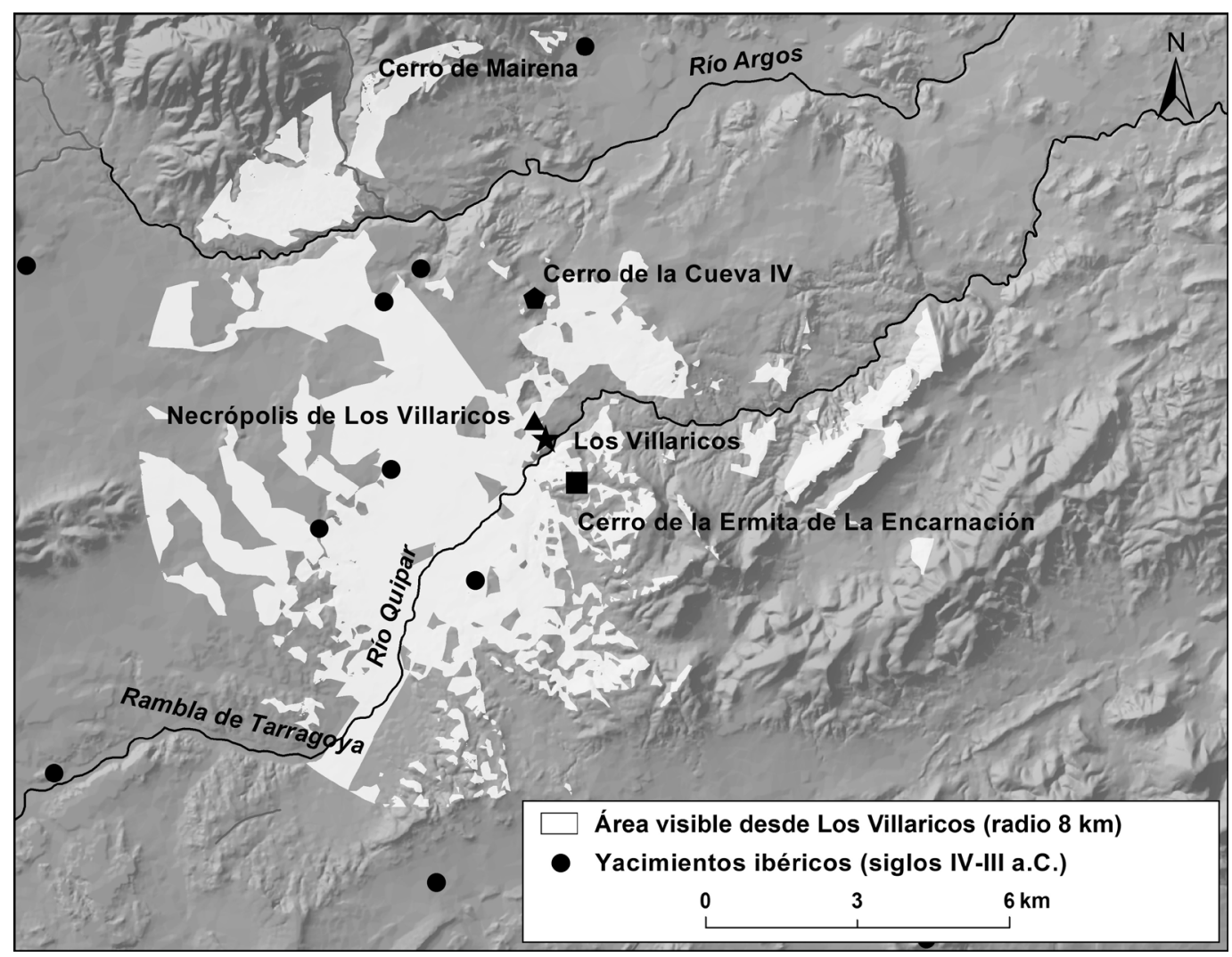

Figura 5. Control visual del valle y de los yacimientos ibéricos desde el oppidum de Los Villaricos. Fuente: elaboración propia.

Finalmente, como hemos indicado, un último aspecto que nos aporta información sobre el santuario permitiendo encuadrarlo en el paisaje del valle para comprender mejor su carácter, es el referido a su relación con el poblamiento ibérico documentado en este sector regional y su inserción en el modelo de ocupación que define esta área desde el siglo IV a.C. y hasta el periodo romano.

Una de las primeras cuestiones que se advierten al analizar el poblamiento en este sector del valle del Quípar es la ausencia de asentamientos que, al margen del oppidum de Los Villaricos, aparezcan situados en el entorno inmediato del santuario, área que debió ser explotada directamente por el citado núcleo (López-Mondéjar, 2010a). Más allá de dicho sector, coincidiendo con el desarrollo tanto del santuario como del oppidum, se observa a partir del siglo IV a.C. una colonización del valle a través de una red de centros secundarios que no tenemos documentada para la centuria anterior. Tales núcleos debieron estar vinculados al desarrollo de actividades agropecuarias, tal y como parece reflejar su emplazamiento en aquellas zonas más aptas para las mismas, y los propios materiales recuperados en algunos de ellos, como en la ya citada zona de Archivel (Brotóns, 2008). Ninguno de ellos alcanza la extensión del oppidum ni presenta defensas naturales o artificiales similares a las 
de aquel, que debió funcionar como núcleo aglutinador de dichas poblaciones dispersas en el valle y en cierta medida como garante de sus actividades económicas y de su seguridad.

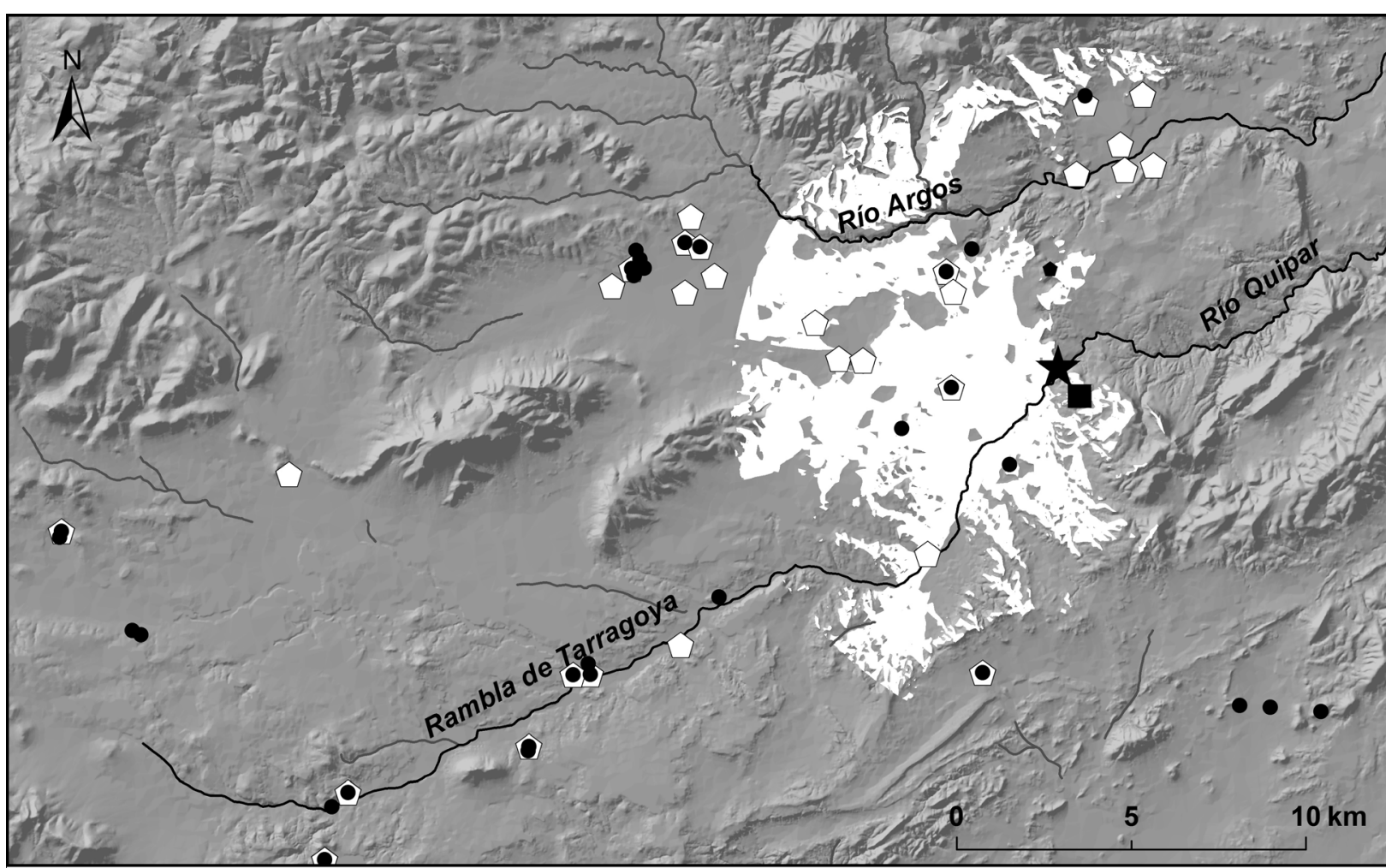

\. Los Villaricos

- Cerro de la Ermita de La Encarnación

- Yacimientos ibéricos (IV-III a.C.)
Yacimientos iberorromanos (II-I a.C.)

Control visual del Cerro de la Ermita de La Encarnación (8 km)

Figura 6. Control visual del valle del Quípar desde el Cerro de la Ermita de La Encarnación y distribución del poblamiento ibérico (IV-III a.C.) e ibero-romano (II-I a.C.) en la comarca. Fuente: elaboración propia.

Precisamente dicho rol vendría además reforzado por esa vinculación entre oppidum y santuario. Este último actuaría también como elemento de control y protección para los habitantes del valle, especialmente si tenemos presente que las excavaciones desarrolladas en el mismo han llevado a relacionar ese espacio de culto con una divinidad vinculada a la fecundidad (Brotóns, 2007) y que, por tanto, jugaría un papel esencial en la explotación de todo el territorio del oppidum. El caso de La Encarnación no es además el único documentado en este sentido en el Sureste, sino que tenemos paralelos similares en otros importantes santuarios murcianos como los localizados en Coimbra del Barranco Ancho y La Luz (García, Iniesta y Page, 1991-1992; Lillo, 1995-1996). Los 'beneficios' desprendidos de los rituales desarrollados en el santuario, como las libaciones de leche y miel documentadas (Ramallo y Brotóns, 1997, p. 261), no fueron exclusivos para los habitantes del oppidum, sino también para los de esos asentamientos rurales dependientes de aquel. A todo ello cabe sumar, además, la enorme cantidad de materiales recuperados en el santuario. Todos ellos lo presentan como un lugar de culto que debió ser ampliamente conocido y frecuentado, no sólo por los habitantes del oppidum sino también por los de otros núcleos emplazados en las proximidades (Ramallo et al., 1998). Desde esta perspectiva, el santuario actuaría, junto al oppidum como elemento aglutinador de dichas poblaciones, dando cohesión al poblamiento del valle y reforzando la vinculación entre el mismo y el núcleo emplazado en Los Villaricos (Figura 5). 
Es precisamente en este marco en el que cabe comprender la evolución del santuario a lo largo de las centurias siguientes y, sobre todo, su continuidad bajo la órbita romana. Así por ejemplo, la monumentalización que experimenta el lugar de culto a partir del siglo II a.C. viene acompañada por un cambio destacado en el poblamiento de todo el valle. Se produce ahora la desaparición de la mayor parte de esos asentamientos que serán sustituidos por una serie de granjas agropecuarias. Éstas, que se situarán en nuevas áreas del valle, constituyen el primer paso hacia el modelo de ocupación que definirá esta zona en época altoimperial (Brotóns y López-Mondéjar, 2010) (Figura 6). El desarrollo del santuario se presenta por tanto ligado a las transformaciones sociopolíticas que experimenta no sólo el oppidum, sino la totalidad del poblamiento localizado en su territorio.

En conexión con esta idea no podemos olvidar, como ya apuntábamos, el desarrollo paralelo que parecen experimentar tanto La Encarnación como Los Villaricos en pleno siglo IV a.C. (Ros et al., 2016). Precisamente tal desarrollo coincide en toda el área regional con el de otros grandes santuarios ibéricos, los cuales surgirán también al amparo de destacados núcleos fortificados, mostrando así un modelo similar al documentado en otros ámbitos ibéricos, donde se ha vinculado la aparición de dichos espacios de culto con el proceso de consolidación de los grandes oppida en el territorio (Ruiz y Molinos, 2002). En el caso del Noroeste murciano lo que parece claro, como se ha señalado también para La Serreta de Alcoy y otros oppida del Sureste, la instalación del santuario supuso la concentración de las funciones religiosas, políticas y económicas en torno al oppidum, al tiempo que reforzó su valor simbólico y su carácter central en el paisaje del valle y entre los nuevos centros secundarios surgidos en esa cuarta centuria (Brun, 20011; Grau, 2000; Santos, 1994).

Precisamente, y atendiendo a ese papel central en el valle de ambos yacimientos, oppidum y santuario, uno de los aspectos que llama la atención es su localización en una zona límite del mismo. El ya indicado carácter estratégico de este sector y la amplia visibilidad que desde él se tiene del valle medio-alto del Quípar son factores clave para comprender la localización de estos dos centros. En el caso del santuario, además, los paralelos documentados en otras áreas nos hacen llevar nuestra atención a su emplazamiento en el límite septentrional del territorio del oppidum. El papel de los lugares de culto como marcadores territoriales es una cuestión que vemos en todo el Mediterráneo prerromano, incluido el mundo ibérico (Ruiz y Molinos, 2002). En muchos casos la posición en la que se situaron determinados santuarios extraurbanos no fue casual sino que respondió a unos criterios y objetivos concretos, como fijar un límite o subrayar la presencia de uno ya establecido (Veronese, 2007; Zifferero, 2002). Su ubicación en puntos fronterizos y en lugares clave de paso, como ocurre con La Luz, El Cigarralejo, Coimbra del Barranco Ancho, el Cerro de los Santos, o el propio Cerro de la Ermita de La Encarnación, pudo responder además a un intento de poner bajo protección divina posibles puntos críticos o de especial interés como serían los límites de ese territorio (Angás, 2005; Uroz, 2008; Zifferero, 2002). En Grecia y en el ámbito colonial griego los santuarios funcionaron como marcadores de áreas de influencia y garantes de los límites de la comunidad, y estuvieron en conexión con el núcleo urbano y su expansión en el territorio (Greco, 2009; Veronese, 2007; Zifferero, 2002). También en el ámbito itálico se han identificado santuarios con funciones similares instalados en los confines territoriales de ciudades etruscas, como Vulci, Populonia y la propia Roma. El área controlada por esta última tenía, ya desde los siglos VIII-VII a.C., unos límites bien definidos y marcados por lugares sacros junto a los principales ejes viarios (Baci, 2006; Celuzza, 2002; Zifferero, 2002). En el caso del mundo ibérico el mejor ejemplo lo encontramos sin duda en el área de Jaén, donde los santuarios funcionaron como elementos clave en la construcción y delimitación de los territorios de los oppida (Rueda, 2011; Ruiz y Molinos, 2002), pero también en otros ámbitos como el alicantino (Grau, 2010; Grau y Amorós, 2013). Según Moneo (2003) los santuarios de este tipo suelen localizarse en zonas excéntricas del territorio, próximos al núcleo principal del mismo y en puntos elevados, representando el interés y el dominio de ese asentamiento fortificado sobre las tierras explotadas.

En el caso de La Encarnación su emplazamiento ofrece varios aspectos interesantes a tener presentes. En primer lugar el santuario se sitúa, como apuntábamos, en el sector más septentrional del área sobre la que el oppidum de Los Villaricos ejerció un control más directo. La propia geografía 
de la zona impediría a este asentamiento dominar visualmente aquellos territorios situados al norte del Estrecho de Las Cuevas donde se documenta durante los siglos IV-III a.C. un único centro (Cerro de Mairena) (Figura 5). El vacío poblacional se extiende hasta alcanzar el entorno de la actual población de Cehegín y el núcleo ibérico instalado en el Cabezo Roenas. En segundo lugar, también la cuenca visual de Los Villaricos y la del propio santuario, aparecen orientadas hacia el sur-suroeste, englobando el valle medio-alto del Quípar y el sector de altiplanos que conecta con el curso del Argos. Todo el sector septentrional, en cambio, escapa a su control visual (Figuras 5 y 6). Por otro lado, cabe recordar la presencia del yacimiento instalado en el Cerro de la Cueva IV (Figura 3). Su posición le permitió controlar aquellos territorios localizados al norte del Estrecho y que escapaban visualmente al oppidum, con el que, además, tuvo una conexión visual directa, vigilando así los accesos desde ese sector al territorio más directamente vinculado a Los Villaricos (López-Mondéjar, 2010a).

Finalmente, resultan también de interés los paralelos que ofrece el mundo itálico. En éste fueron precisamente aquellos lugares de culto con un carácter territorial los que se monumentalizaron con la presencia romana (Tagliente, Fresa y Bottini, 1991). En todos ellos, el destacado papel territorial que habían jugado a lo largo de las centurias previas estuvo claramente en conexión con su continuidad y su transformación edilicia. Roma se mostró así interesada en continuar manteniendo a dichos santuarios como elementos clave en la articulación del territorio, proceso que, salvando las distancias, puede ayudarnos a comprender en este segundo nivel de análisis, la relación entre La Encarnación y el territorio de Los Villaricos y, sobre todo, la monumentalización de dicho espacio de culto tras la llegada de Roma.

\section{Más allá del territorio del oppidum: La Encarnación en el Sureste ibérico}

Más allá de las fronteras del territorio de Los Villaricos, la inserción de este santuario en el marco del paisaje ibérico del Sureste resulta el nivel más complejo de abordar. La información disponible para época ibérica aporta pocos datos en esta línea. A pesar de ello, su estudio en el paisaje y algunos datos materiales pueden ser útiles para aproximarnos a esta última cuestión.

Se ha constatado que determinados lugares de culto, sobre todo aquellos emplazados junto a vías de comunicación, funcionaron como puntos de encuentro a nivel interregional (Moneo, 2003). Su posición, en ocasiones en encrucijadas de caminos los convirtió en centros de atracción de gentes de diversas comunidades o espacios de reunión entre sus dirigentes (Zifferero, 2002). En este sentido, la localización de La Encarnación, en uno de los principales ejes del Sureste permitiría plantear su frecuentación por gentes de diversas comunidades, como se ha observado en otros santuarios emplazados en vías clave de tránsito y en encrucijadas de caminos (García, 2015; Gusi, 1997).

Ahora bien, junto a dicha posición ¿existen otros elementos que denoten esa frecuentación? En el caso del vecino santuario del Cerro de los Santos se ha interpretado en esta línea la aparición de exvotos con estilos muy distintos (Moneo, 2003). En La Encarnación la cultura material parece mostrar, de igual modo, una amplia heterogeneidad, en la que se mezclan elementos propios del ámbito levantino y el valle del Segura con otros característicos del área oriental andaluza (LópezMondéjar, 2009). ¿Es posible que también aquí, de modo similar a lo indicado para el Cerro de los Santos, dicha variedad deba ponerse precisamente en conexión con la presencia de peregrinos procedentes de áreas muy distintas? Lo que sí es cierto es que la localización de ambos santuarios y su monumentalización les otorgan un carácter especial dentro de los espacios de culto ibéricos del Sureste.

Precisamente el emplazamiento de La Encarnación ha llevado a algunos autores a plantear su posible carácter 'supraterritorial' en relación con su localización fronteriza entre las áreas ibéricas citadas en las fuentes clásicas ${ }^{5}$. Teóricamente, según dichos trabajos, el santuario se habría situado

5 Ptolomeo (Guía de Geografía II 6, 60) sitúa en esta zona la ciudad de Asso, identificada con el oppidum de 
en la 'frontera' bastetana, al igual que otros como el Cerro de Los Santos, Collado de Los Jardines o La Luz, se situaron respectivamente en los límites oretanos y contestanos (Moneo, 2003; Ruano, 1988). Este planteamiento responde a la tradicional delimitación entre bastetanos y contestanos que ha querido establecerse en esta zona del Sureste y a la identificación de Los Villaricos con la población de Asso, emplazada según Ptolomeo en el límite bastetano (Yelo, 1984). Del mismo modo, el hecho de que el límite de las nuevas provincias romanas se localice en esta misma zona del Sureste ha llevado a vincular aquellas con esa división anterior entre bastetanos y contestanos (Moneo, 2003).

Todos estos planteamientos no están sin embargo exentos de una variada problemática, que abarca desde el análisis de las propias fuentes hasta la imposibilidad de hablar realmente de 'límites' entre grupos ibéricos intentando trazar 'fronteras' inmutables entre ellos (Quesada, 2008). Es cierto que en el ámbito ibérico se han puesto en conexión determinados santuarios con ciertos grupos étnicos citados en las fuentes, si bien desde una perspectiva distinta a la indicada en el caso de La Encarnación. Disponemos de ejemplos bien documentados del desarrollo, a partir del siglo III a.C., de proyectos étnicos superiores a los meramente comarcales en los que los santuarios jugaron un importante papel, como en el ámbito de Jaén. Aquí, dicho proceso culminó en la configuración de la nueva etnia oretana que vemos señalada en las fuentes clásicas (Ruiz y Molinos, 2002).

En el caso concreto de La Encarnación, y en base a los datos disponibles por el momento, no podemos plantear esa proyección étnica, ni su vinculación con alguno de esos grupos citados en las fuentes. Del mismo modo, tampoco podemos pretender ver en dicho santuario el resultado de un proyecto territorial superior al del territorio político del oppidum, similar al documentado en La Serreta, en el área alicantina (Grau, 2000). En nuestra opinión, el santuario ibérico de La Encarnación parece más bien vinculado al oppidum de Los Villaricos y a su territorio.

Una cuestión distinta es el alcance que dicho santuario pudo tener tras la llegada de Roma y los posibles cambios que su monumentalización, con la construcción de dos templos al estilo itálico, pudo implicar en este sentido. El desarrollo del poblamiento en el área del Noroeste regional, así como en otros sectores murcianos (López-Mondéjar, 2009), muestra que Roma centró su interés inicialmente en mantener el status quo y sobre todo en 'utilizar' aquellas estructuras organizativas que encontró en funcionamiento a su llegada. En este sentido, el papel vertebrador de este santuario como lugar de referencia en todo este territorio jugó sin duda a favor del mismo, sin que podamos descartar, en este periodo, que incluso se ampliase su área de influencia a otros sectores próximos del Noroeste, especialmente si tenemos presente que se trata del único santuario ibérico del ámbito regional que experimenta tal transformación edilicia.

\section{A modo de síntesis: lugares de culto y territorio en el Sureste ibérico}

Los distintos aspectos analizados pretenden ampliar nuestra visión de los espacios de culto ibéricos del Sureste peninsular, y permiten advertir su papel más allá del ámbito estrictamente ligado al culto y a la religión de las comunidades de finales de la Edad del Hierro en estos territorios. El estudio del caso concreto del santuario de La Encarnación, uno de los mejor conocidos a nivel arqueológico, pone sin duda de manifiesto el triple rol desarrollado por este centro como elemento vertebrador a nivel social, político y organizativo. En primer lugar constituyó un espacio de representación social para la élite residente en el oppidum y de 'encuentro' entre aquella y el resto de la comunidad (López-Mondéjar 2014). Por otro lado fortaleció los vínculos entre el oppidum y su territorio. En este sentido no sólo completó el control real ejercido desde Los Villaricos con un control simbólico, sino que también funcionó como un espacio común, de cohesión, para los múltiples centros dispersos por el valle. Por último, constituyó un elemento de diferenciación social pero también de contacto, reforzando la identidad de los residentes en el territorio de Los Villaricos (Santos, 1994).

Los Villaricos de acuerdo con las inscripciones aparecidas en la zona (CIL II, 5941 y 5942$)$. Dicho autor cita dicha población como uno de los límites de los bastetanos en el Sureste.

Panta Rei (2017), 23 - 40 
El ejemplo de La Encarnación muestra de este modo el amplio papel que jugaron ciertos lugares de culto ibéricos del Sureste y muchos de los planteamientos señalados en conexión con él pueden hacerse extensivos al estudio de otros grandes santuarios de esta área peninsular. Así, a lo largo de los siglos IV-III a.C., yacimientos como El Cigarralejo, La Luz o el santuario de Coimbra del Barranco Ancho pueden analizarse también a los tres niveles indicados, mostrando claros paralelos con La Encarnación.

En primer lugar, la localización de todos y cada uno de ellos refleja su conexión con los principales oppida regionales, al tiempo que su cultura material los vincula con la élite residente en estos centros. Así, por ejemplo, en el caso de La Luz cabe señalar el hallazgo de figurillas de guerreros y falcatas votivas (García, Hernández, Iniesta y Page, 1997; Lillo, 1986-1987), y la significativa presencia de abundantes materiales de importación ligados al consumo de vino. Éstos sólo pueden comprenderse en relación con un grupo dirigente capaz de adquirir dichos productos a través de los circuitos de intercambio para su uso ritual en este santuario (Lillo, 1995-1996). En El Cigarralejo, por su parte, las numerosas imágenes de caballos aparecidas pueden interpretarse también como símbolo del estatus y la fuerza de la élite residente en el vecino oppidum, como se advierte en otros ámbitos del Mediterráneo en estos momentos (Bradley, 1997; Cardete, 2003; Colonna, 1985). En este mismo santuario, el hallazgo de elementos con restos de escritura permite incluir dicho lugar de culto, como otros del Sureste, en los circuitos de escritura, reflejo según Aranegui de la presencia de una élite o al menos de un grupo letrado, residente en el oppidum y a la cabeza de la gestión de la comunidad y del santuario (Aranegui, 1994).

Más allá del oppidum y de su relación con esos grupos dirigentes, los grandes santuarios regionales jugaron también un destacado papel a nivel territorial. Se distribuyeron así controlando los principales valles regionales, en torno a los que se organiza el poblamiento y a los que se circunscriben los territorios políticos de cada uno de los oppida a los que aparecen asociados (La Luz controló el paso del Segura y su unión con el Guadalentín, Coimbra del Barranco Ancho el acceso a las tierras meseteñas, y El Cigarralejo el eje definido por el río Mula hacia el interior regional) (Figura 1).

Como elementos vinculados a dichos oppida, contribuyeron asimismo a consolidar el dominio de éstos sobre el territorio, ampliando dicho control de forma simbólica más allá de los límites del espacio urbano. Como en La Encarnación, todos ellos ofrecen una amplia visibilidad del entorno, ocupando posiciones dominantes en el paisaje y con un amplio control visual de las tierras y vías de comunicación.

Al mismo tiempo, los propios rituales celebrados en esos santuarios, como se ha documentado también en La Luz, estuvieron ligados a favorecer la fertilidad agrícola en el territorio de los oppida. En el caso de este último santuario, por ejemplo, la presencia de un posible graderío o comitium se ha interpretado en conexión con una amplia participación comunitaria en los rituales (Lillo, 19951996).

Finalmente, a una escala más amplia, no podemos por el momento afirmar que los lugares de culto del Sureste, incluida La Encarnación, y a pesar de lo que ha querido indicarse en alguna ocasión, estuvieran tras la creación de proyectos étnicos a nivel supraterritorial, como se ha señalado para los santuarios de otros ámbitos ibéricos próximos. Aun así, sí contribuyeron a dar cohesión al territorio de cada uno de esos oppida, desde un punto de vista interno pero también externo, frente a otras comunidades, al tiempo que pudieron actuar como espacios de contacto entre ellas. La cantidad y diversidad de las ofrendas documentadas en santuarios como La Luz, La Encarnación o Coimbra del Barranco Ancho los muestran 'abiertos' a una amplia y variada frecuentación. En el caso de La Luz es en esta línea en la que cabe interpretar la alta proporción de productos importados, y el hallazgo de almacenes, talleres y hornos metalúrgicos, destinados a la producción masiva de exvotos de bronce para los fieles que acudían al santuario. Todo ello testimoniaría, como indicaba P. Lillo, la afluencia que debió tener este santuario, en el que se darían cita "peregrinos, romeros y mercaderes" (Lillo 1995-1996, pp. 110-111).

En general, todo lo indicado muestra que los santuarios del Sureste fueron mucho más que 
simples lugares de culto, como a veces parecen reflejar los estudios centrados en el análisis de las ofrendas votivas y restos materiales. En el caso concreto de La Encarnación el santuario constituyó un espacio social y político esencial en la vida de las comunidades ibéricas de esta área regional murciana. Sólo comprendiendo todas y cada una de sus facetas es posible entender el verdadero valor de dicho yacimiento en el marco del paisaje ibérico de esta zona. Es más, será con la presencia romana cuando todos y cada uno de esos aspectos se revelarán como fundamentales e influirán de forma decisiva en su transformación edilicia. Como en otros sectores peninsulares y del Mediterráneo, algunos lugares de culto del Sureste se convirtieron durante los primeros momentos de la expansión de Roma en elementos a través de los cuales muchas comunidades se aferraron a sus tradiciones, pero también en espacios de integración sociopolítica y cultural. Consciente del valor de los mismos en el marco territorial y en la propia mentalidad de esas comunidades, no es de extrañar que Roma estuviese interesada en favorecer la continuidad y el desarrollo de determinados espacios, siendo el caso de La Encarnación, con sus dos templos de estilo itálico, uno de los más llamativos de todo el Sureste ibérico. En cualquier caso, y como reflejan otros santuarios regionales, dicha continuidad no puede hacerse extensiva a todos los espacios de culto de esta zona. El panorama que se presenta tras la conquista romana es muy heterogéneo, advirtiéndose importantes cambios ideológicos que sin duda afectarán también a esos yacimientos. Así, no todos ellos ofrecerán una clara continuidad, y será Roma la que, en última instancia, opte o no por reforzar y mantener esos espacios en función de sus propios intereses y del contexto poblacional que encontrará en cada territorio.

\section{Abreviaturas}

CIL II. Hübner, E. Corpus Inscriptionum Latinarum, II. Hispania. Berlín: Berlín-Brandenburg Academy of Sciencies and Humanities. 1869.

\section{Bibliografía}

Adroher, A. M. y López, A. (2004). El territorio de las altiplanicies granadinas entre la Prehistoria y la Edad Media: arqueología en Puebla de Don Fabrique [(1995-2002)|. Sevilla: Consejería de Cultura-Gobierno de Andalucía.

Alcock, S. y Osborne, R. (1994). Placing the gods. Sanctuaries and Sacred space in Ancient Greece. Oxford: Ed. Clarendon.

Angás, J. (2005). Santuarios como indicadores de frontera en el territorio noroccidental de Vulci (siglos VII-III a.C. Italia centro-tirrénica). Salduie, 5, 65-94.

Aranegui, C. (1994). Iberica Sacra Loca. Entre el Cabo de la Nao, Cartagena y el Cerro de los Santos. Revista de Estudios Ibéricos, 1, 115-138.

Aranegui, C. (2011). Lo divino en femenino. ¿Hombres o dioses?: una nueva mirada a la escultura del mundo ibérico: Museo Arqueológico Regional, Alcalá de Henares, Madrid: del 8 de julio al 16 de octubre de 2011 (pp. 133-158). Madrid: Museo Arqueológico Regional.

Baci, M. (2006). I confini del territorio di Populonia al tempo della Romanizzazione. Nuovi dati per un'ipotesi di ricostruzione. Materiali per Populonia, 5, 445-451.

Bradley, G. (1997). Archaic sanctuaries in Umbria. Cahiers du Centre G. Glotz, 8, 111-129.

Brotóns, F. (1995). El poblamiento romano en el valle alto del Quípar (Rambla de Tarragoya). En Noguera, J. M. (coord.), Poblamiento rural romano en el Sureste de Hispania (pp. 247-274). Murcia: Editum.

Brotóns, F. (2007). Las terracotas en forma de cabeza femenina del santuario ibero-romano de La Encarnación (Caravaca de la Cruz - Murcia). En Marín, M. C. y Horn, F. (eds.), Imagen y culto en la Iberia prerromana: los pebeteros en forma de cabeza femenina (pp. 313-338). Sevilla: Universidad de Sevilla.

Brotóns, F. (2008). La necrópolis tumular ibérica de "El Villar de Archivel" (Caravaca de la Cruz). En I Congreso Internacional de Arqueología Ibérica Bastetana (pp. 23-42). Madrid: Universidad 
Autónoma de Madrid-Universidad de Granada.

Brotóns, F. y López-Mondéjar, L. (2010). Poblamiento rural romano en el Noroeste. En Noguera, J. M. (ed.), Poblamiento rural romano en el Sureste de Hispania 15 años después (pp. 413-438). Murcia: Editum.

Brotóns, F. y Ramallo, S. F. (1994). Un santuario suburbano: La Encarnación de Caravaca. En Congreso Internacional de Arqueología Clásica (14, Tarragona) (pp. 74-75). Tarragona: Consejo Superior de Investigaciones Científicas.

Brotóns, F. y Ramallo, S. F. (1999). Excavaciones arqueológicas durante el año 1993 en el Cerro de la Ermita de La Encarnación (Caravaca de la Cruz). Memorias de Arqueología, 8 (1993), 226-237.

Brotóns, F. y Ramallo, S. F. (2010). Ornamento y símbolo: las ofrendas de oro y plata en el santuario ibérico del Cerro de la Ermita de La Encarnación de Caravaca. En Tortosa, T. y Celestino, S. (eds.), Debate en torno a la religiosidad protohistórica. Anejos de Archivo Español de Arqueología, LV (pp. 123-168). Madrid: Centro Superior de Investigaciones Científicas.

Brun, P. (2001). Échelles d'intégration politique et contrôle des moyens de production en Europe au cours du ler millénaire av. J.-C. En Berrocal, L. y Gardes, P. (coords.), Entre celtas e íberos. Las poblaciones protohistóricas de las Galias e Hispania (pp. 29-43). Madrid: Casa de VelázquezReal Academia de la Historia.

Cardete, M. C. (2003). Identidad y religión: el santuario de Apolo en Basas. Studia Historica. Historia Antigua, 21, 47-74.

Celuzza, M. (2002). La Romanizzazione: etruschi e romani fra 311 e 123 a.C. En Carandini, A. y Cambi, F. (eds.), Paesaggi d'Etruria (pp. 103-113). Roma: Edizioni di Storia e Letteratura.

Colonna, G. (1985). Santuari d'Etruria. Milán: Electa.

Cuadrado, E. (1945). Introducción al estudio arqueológico del Estrecho de la Encarnación. Boletín Arqueológico del Sudeste Español, 2, 124-134.

Cultraro, M. (2005). Dimore sacre e luoghi del tempo: Appunti per uno studio della percezione dello spazio sacro nella Sicilia dell'Antica Età del Bronzo. En Papers in Italian Archaeology VI. Communities and settlements from the Neolithic to the Early Medieval Period. Proceedings of the 6 Conference of Italian Archaeology held at the University of Groningen, Groningen Institute of Archaeology, vol. I (pp. 588-595). Oxford: BAR International Series.

García, J. M., Iniesta, A. y Page, V. (1991-1992). El santuario ibérico de Coimbra del Barranco Ancho (Jumilla, Murcia). Anales de Prehistoria y Arqueología de la Universidad de Murcia, 7-8, 75-82.

García, J. M., Hernández, E., Iniesta, A. y Page, V. (1997). El Santuario de Coimbra del Barranco Ancho (Jumilla, Murcia) a la luz de los nuevos hallazgos. Quadernos de Prehistòria i Arqueologia de Castellò, 18, 239-256.

García, J. (2015). El Cerro de los Santos: paisaje, negociación social y ritualidad entre el mundo ibérico y el hispano. Archivo español de arqueología, 88, 85-104.

Grau, I. (2000). Territorio y lugares de culto en el área central de la Contestania ibérica. Quadernos de Prehistòria i Arqueologia de Castellò, 21, 195-225.

Grau, I. (2010). Paisajes sagrados del área central de la Contestania ibérica. En Tortosa, T. y Celestino, S. (eds.), Debate en torno a la religiosidad protohistórica. Anejos de Archivo Español de Arqueología, LV (pp. 101-122). Madrid: Centro Superior de Investigaciones Científicas.

Grau, I. (2011). Límite, confín, margen, frontera... conceptos y nociones en la Antigua Iberia. En Prados, F., García, I. y Bernard, G. (eds.), Confines. El extremo del mundo durante la Antigüedad (pp. 23-47). Alicante: Universidad de Alicante.

Grau, I. y Amorós, I. (2013). La delimitación simbólica de los espacios territoriales ibéricos: el culto en el confín y las cuevas-santuario. En Rísquez, C. y Rueda, C. (eds.), Santuarios iberos: territorio, ritualidad y memoria. 5 Actas del Congreso "El santuario de la Cueva de la Lobera de Castellar. 1912-2012 (pp. 183-212). Jaén: Asociación para el desarrollo rural de la Comarca de El Condado.

Greco, E. (2009). Spazi sacri, assetti urbani e dinamiche territoriali nella Magna Grecia. En Mateos, 
P., Celestino, S., Pizzo, A. y Tortosa, T. (eds.), Santuarios, oppida y ciudades: arquitectura sacra en el origen y desarrollo urbano del Mediterráneo occidental. Anejos de Archivo Español de Arqueología, XLV (pp. 11-28). Madrid: Centro Superior de Investigaciones Científicas.

Gusi, F. (1997). Lugares sagrados, divinidades, cultos y rituales en el levante de Iberia. Quadernos de Prehistòria i Arqueologia de Castellò, 18, 171-209.

Lillo, P. A. (1986-1987). Un singular tipo de exvoto: las pequeñas falcatas. Cuadernos de Prehistoria y Arqueología de la Universidad Autónoma de Madrid, 13-14(2), 33-46.

Lillo, P. A. (1995-1996). El peribolos del templo del santuario de La Luz y el contexto de la cabeza marmórea de la diosa. Anales de Prehistoria y Arqueología de la Universidad de Murcia, 1112, 95-128.

López-Mondéjar, L. (2009). La Bastetania ibérica y su integración en el mundo romano. Tesis doctoral inédita, Universidad de Murcia.

López-Mondéjar, L. (2010a). El poblamiento ibérico en el Noroeste murciano: una aproximación al oppidum de Los Villaricos a través de su patrón de asentamiento. Cuadernos de Prehistoria y Arqueología de la Universidad Autónoma de Madrid, 36, 7-25.

López-Mondéjar, L. (2010b). Los santuarios ibéricos del valle del Quípar (Murcia): carácter, localización y paralelos en el marco del Sureste peninsular. Quadernos de Prehistoria y Arqueologia de Castellò, 28, 175-189.

López-Mondéjar, L. (2014). Santuarios y poder ideológico en el Sureste ibérico peninsular (siglos IV-III a.C.): paisajes, ceremonias y símbolos. Munibe. Antropologia-Arkeologia, 65, 157-175.

Moneo, T. (2003). Religio Iberica. Santuarios, ritos y divinidades. Madrid: Real Academia de la Historia.

Quesada, F. (2008). Entre bastetanos y turdetanos: arqueología ibérica en una zona de fronteras. En I Congreso Internacional de Arqueología Ibérica Bastetana (pp. 147-177). Madrid: Universidad Autónoma de Madrid-Universidad de Granada.

Ramallo, S. F. (1991). Un santuario de época tardorrepublicana en la Encarnación. Cuadernos de Arquitectura romana, 1, 39-65.

Ramallo, S. F. (1993). La monumentalización de los santuarios ibéricos en época tardo-republicana, Ostraka II, 1, 117-144.

Ramallo, S. F. (2000). La realidad arqueológica de la 'influencia' púnica en el desarrollo de los santuarios ibéricos del Sureste de la Península Ibérica. Treballs del Museu Arqueologic d'Eivissa e Formentera. XIV Jornadas de Arqueología Fenicio-Púnica, 46, 185-217.

Ramallo, S. F. y Arana, R. (1993). Terracotas arquitectónicas del Santuario de la Encarnación (Caravaca de la Cruz, Murcia). Archivo Español de Arqueología, 66, 71-98.

Ramallo, S. F. y Brotóns, F. (1997). El santuario ibérico de La Encarnación (Caravaca de la Cruz, Murcia). Quadernos de Prehistòria i Arqueologia de Castellò, 18, 257-268.

Ramallo, S. F. y Brotóns, F. (1999). El Santuario ibérico de El Cerro de los Santos. En Blánquez, J. y Roldán, L. (eds.), La cultura ibérica a través de la fotografía de principios de siglo I (169-178). Madrid: Patrimonio Nacional.

Ramallo, S. F. y Brotons, F. (2014). Depósitos votivos y ritos en los santuarios ibéricos e iberoromanos. Continuidades y rupturas a través de las evidencias de culto en el santuario del Cerro de la Ermita de La Encarnación (Caravaca de la Cruz, Murcia). En Tortosa, T. (ed.), Diálogos de identidades. Bajo el prisma de las manifestaciones religiosas en el ámbito mediterráneo (s. III a.C.-s. I d.C.). Anejos de Archivo Español de Arqueología, LXXII (pp. 17-44). Madrid: Centro Superior de Investigaciones Científicas.

Ramallo, S. F., Noguera, J. M. y Brotóns, F. (1998). El Cerro de los Santos y la monumentalización de los santuarios ibéricos tardíos. Revista de Estudios Ibéricos, 3, 11-69.

Ros, M. M., Brotóns, F. y Ramallo, S. F. (2016). Aproximación al horizonte Preibérico - Ibérico Antiguo en el Noroeste murciano: la prospección del oppidum de Los Villares del Estrecho de las Cuevas de La Encarnación (Caravaca de la Cruz). Anejos a Cuadernos de Prehistoria y Arqueología de la Universidad Autónoma de Madrid, 2, 219-239. 
Ruano, E. (1988). El Cerro de los Santos (Montealegre del Castillo): una nueva interpretación del santuario. Cuadernos de Prehistoria y Arqueología de la Universidad Autónoma de Madrid, 15, 253-273.

Ruano, E. y San Nicolás, M. (1993). Exvotos ibéricos procedentes de 'La Encarnación' (Caravaca). Verdolay, 2, 101-107.

Rueda, C. (2011). Territorio, culto e iconografía en los santuarios iberos del alto Guadalquivir. Jaén: Universidad de Jaén.

Ruiz, A. y Molinos, M. (2002). El proceso histórico de los iberos en el valle alto del río Guadalquivir. En Molinos, M. y Zifferero, A. (eds.), Primi popoli d'Europa. Proposte e riflessioni sulle origini della civiltà nell'Europa mediterranea (pp. 291-300). Florencia: All'Insegna del Giglio.

Santos, J. A. (1994). Cambios sociales y culturales en época ibérica: el caso del Sureste. Madrid: Cran.

Tagliente, M., Fresa, M. P. y Bottini, A. (1991). Relazione sull'area daunio-lucana e sul santuario di Lavello. En Mertens, J. y Lambrechts, R. (eds.), Comunità indigene e problemi della romanizzazione nell'Italia centro-meridionale (IV-III sec. av. C.) (pp. 93-104). Bruselas: Brepols.

Uroz, H. (2008). Religión en tiempos de transición: de Iberia a Hispania. En IV Congreso HispanoItaliano histórico-arqueológico. Iberia e Italia (pp. 465-492). Murcia: Tabularium.

Veronese, F. (2007). Lo spazio e la dimensione del sacro. Santuari greci e territorio nella Sicilia arcaica. Padua: Esedra.

Witcher, R. (1999). GIS and Landscapes of Perception. En Gillings, M., Mattingly, D. y Dalen, J. Van (eds.), GIS and Landscape Archaeology (pp. 13-22). Oxford: Oxbow.

Yelo, A. (1984). Asso. Hacia un nuevo planteamiento sobre su localización cerca de Caravaca. Anales de la Universidad de Murcia. Letras, XLII (3-4), 125-137.

Zifferero, A. (2002). La geografia del sacro nelle società complesse:ipotesi per una ricerca sull'Italia medio-tirrenica preromana. En Molinos, M. y Zifferero, A. (eds.), Primi popoli d'Europa. Proposte e riflessioni sulle origini della civiltà nell'Europa mediterranea (pp. 137-156). Florencia: All'Insegna del Giglio. 


\section{Panta Rei}

PANTA REI es una revista digital de investigación orientada a la Historia y otras ciencias afines. Su principal objetivo es la transmisión del conocimiento científico, dando una oportunidad también a los jóvenes investigadores que quieren abrirse camino en el estudio de las ciencias humanas y sociales. Se compone de estudios originales relacionados con la disciplina histórica así como su didáctica y difusión. Las diferentes secciones que componen la revista son: artículos de investigación, entrevistas a profesionales, recensiones de monografías de actualidad y crónicas de congresos o eventos científicos relevantes.

Todos los artículos publicados son objeto de un proceso de revisión a cargo de un mínimo de dos evaluadores, que se consideran expertos en el ámbito temático del artículo propuesto. Nuestro deseo es poder ofrecer unos contenidos rigurosos, de calidad y de interés.

EI CEPOAT (Centro de Estudios del Próximo Oriente y la Antigüedad Tardía de la Universidad de Murcia) es la institución encargada de la coordinación y gestión de la revista, desde donde anualmente se lanzará la convocatoria para aquellos que estén interesados en publicar sus trabajos, siempre relacionados con la Historia, Arqueología, Historia del Arte, Didáctica de las Ciencias Sociales, etc.

PANTA REI is a digital journal focused on History and other sciences related to it. Its main objective is the transmission of scientific knowledge by giving also an opportunity to young researchers who want to make their way in the study of human and social sciences. It is composed by original studies related to History, as well as its didactics and promotion. The different sections of this journal are: research articles, interviews to professionals, recensions on monographs about current issues and reports about congresses or relevant scientific events.

All the articles published are subject to a revision process carried out by a minimum of two reviewers who are considered to be experts in the field of the article proposed. Our wish is to offer rigorous contents with quality and being of interest to the reader.

CEPOAT (Centre of Studies of the Middle East and Late Antiquity of the University of Murcia) is the institution in charge of the coordination and management of this journal. This is the centre from where the call for papers will be launched for all the people interested in publishing their papers, always related to History, Archeology, Art History, Didactics of the Social Sciences, etc. 


\section{Normas de Publicación}

El autor se compromete a enviar trabajos originales, que no se encuentren publicados en otras revistas ni en otros idiomas. Así mismo, el mismo artículo no podrá ser presentado en otras revistas mientras dure el proceso de evaluación.

\section{Envío y presentación de originales}

Los artículos se enviarán exclusivamente a través del correo electrónico a la dirección pantarei@um.es. Los textos serán enviados en formato DOC y las imágenes en formato JPEG o TIFF, y con un tamaño mínimo de 2000 px. Éstas no aparecerán incorporadas en el texto, sino enviadas en archivo aparte y correctamente numeradas según su posición en el texto. Junto al trabajo, se rellenará y enviará un documento aparte en el que se especifiquen los datos del autor siguiendo el modelo disponible en la página Web de la revista.

Para la redacción de los trabajos se tendrá en cuenta el Manual de la American Psychological Association, en su sexta edición. La extensión máxima de los trabajos será de 30 páginas. La tipografía será Arial 11, con interlineado sencillo y sin espacio alguno entre párrafos. El texto deberá ir justificado a ambos márgenes y sin sangría en los primeros párrafos. Los márgenes serán de $2,50 \mathrm{~cm}$. En los casos en los que fuera necesario incorporar notas, éstas irán a pie de página, enumeradas consecutivamente, con tipografía Arial 10, interlineado sencillo y justificadas a ambos márgenes.

Una información más detallada se encuentra disponible en la página http://www.um.es/cepoat/ pantarei.

\section{Proceso de valoración y evaluación}

Una vez recibidos los trabajos, la Revista realizará una primera valoración. Si el trabajo enviado se ajusta a las normas de presentación propuestas, la temática es coincidente con la línea editorial de la revista y posee la calidad científica necesaria, será remitido al consejo asesor para una primera evaluación. Si no es así en este primer paso se puede rechazar directamente los documentos que incumplan claramente la línea editorial.

Será el Consejo Asesor quien indique a la revista la originalidad, relevancia, estructura, redacción, aparato bibliográfico, etc. del trabajo enviado y, para ello, se designará a dos revisores expertos externos que evaluarán cada uno de los trabajos, que pueden formar parte (o no) de este Consejo Asesor. La selección de los revisores se ajustará a la temática y características metodológicas del trabajo. El nombre y filiación de los autores serán eliminados del trabajo para su revisión, así como los revisores actuarán de manera anónima y confidencial.

Los revisores deberán rellenar un informe de evaluación que centrará su atención en aspectos tales como características formales, originalidad y novedad de los trabajos, relevancia de las propuestas y los resultados, calidad metodológica y validez científica.

Una vez terminado el proceso se decidirá la aceptación o no de los mismos y su publicación en el número que sea pertinente, así como las modificaciones susceptibles de ser realizadas para su final publicación. Dicha notificación se enviará únicamente por correo electrónico, en un plazo máximo de seis meses. 


\section{Publishing rules}

The author is committed to submit original papers not having been published in other reviews or in other languages. In this way, it is not allowed for the same paper to be presented in other reviews during the evaluation process.

\section{Submission and presentation of originals}

The articles will be exclusively submitted by email to pantarei@um.es. The texts will be submitted in DOC format and the images in JPEG or TIFF format, and with a minimum size of 2000 px. Images will not be integrated in the text but sent in another file and properly numbered according to their position in the text. Attached to the paper, a document will be filled out and sent where the author's data will be specified following the model available on the website.

The sixth edition of the Manual of the American Psychological Association will be taken into account for the writing of the papers. The length of the papers must not exceed 30 pages. Typography will be Arial 11 , with simple line spacing and no space between paragraphs. The text must be justified on both margins without indentation in the first paragraphs. Margins size will be $2.50 \mathrm{~cm}$. Where it could be necessary the incorporation of notes, they will be at the bottom of the page, consecutively numbered with typography Arial 10, simple line spacing and justified on both margins.

More detailed information is available on the website: http://www.um.es/cepoat/pantarei.

\section{Examination and assessment process}

The Journal will submit the papers to a first examination once received. If the paper follows the presentation guidelines, the subject agrees with the editorial line of this journal, and possess the scientific quality required, it will be sent to the advisory council for a first assessment. If not, the documents which clearly fail to complete the editorial line may be rejected straightaway in this first step.

The Advisory Council will indicate the originality, relevance, structure, writing, bibliography, etc. of the text to the journal; for this purpose, two outside experts will be designated to review the papers; these experts can be (or not) part of this Advisory Council. The selection of the experts will adjust to the subject and methodological characteristics of the paper. Name and affiliation of the author will be eliminated from the text for its review, in this way experts will act anonymously and confidentially.

The experts will fill out an assessment report which will focus on aspects such as formal characteristics, originality and novelty of the papers, relevance and results of the proposal, methodological quality and scientific validity.

Once the process is finished, the acceptance or not of the papers and its publication in the corresponding edition will be decided, as well as the modifications that may be done for its final publication. This notification will be sent by email within 6 months maximum. 



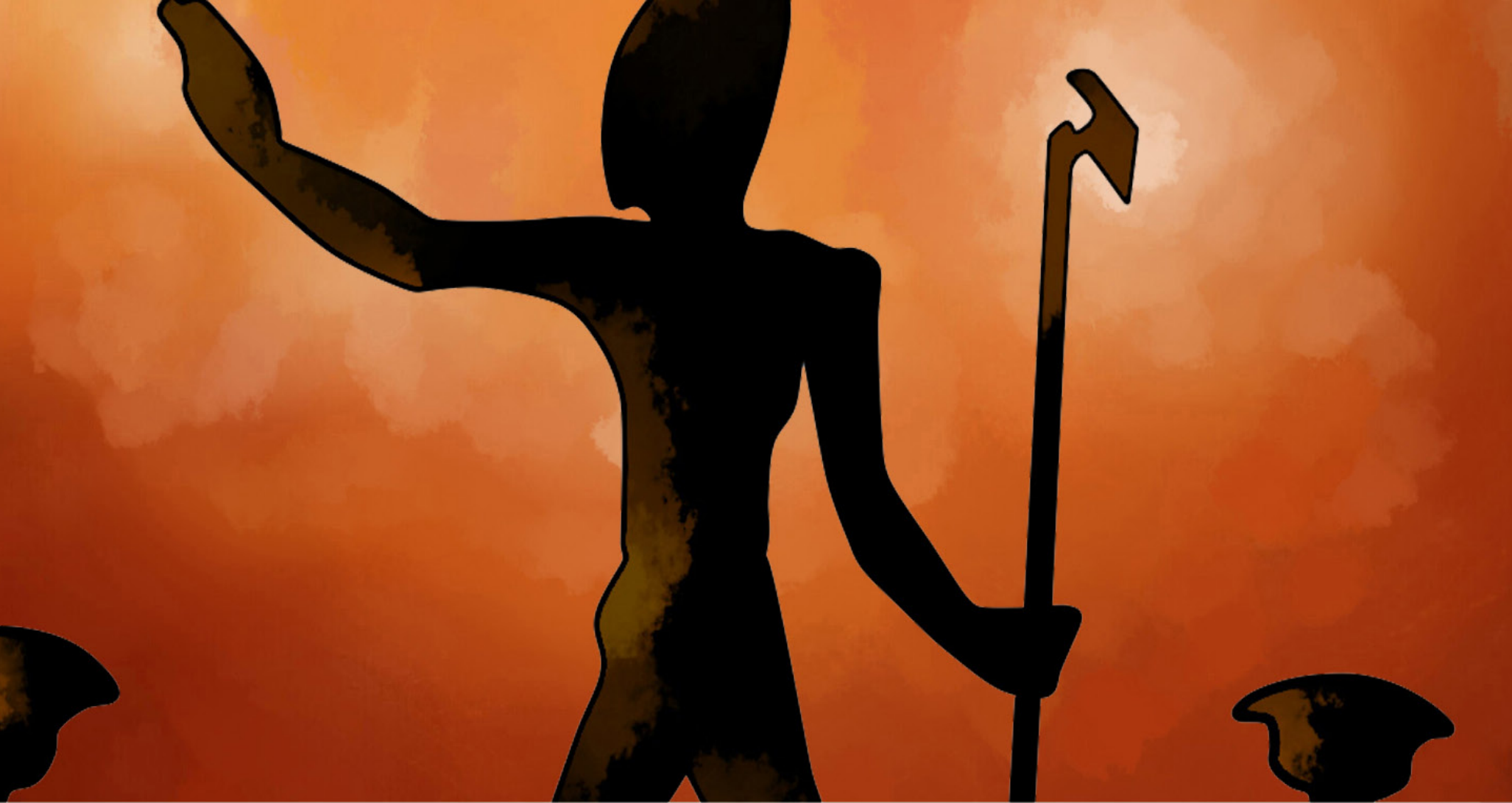

\section{cepoAt}

UNIVERSIDAD DE MURCIA

centro de estudios del

próximo oriente y la

antigüedad tardía 